\title{
Treatment satisfaction with botulinum toxin: a comparison between blepharospasm and cervical dystonia
}

\section{Bernd Leplow \\ Anna Eggebrecht \\ Johannes Pohl}

Department of Psychology, MartinLuther-University Halle-Wittenberg, Halle (Saale), Germany
Correspondence: Bernd Leplow Department of Psychology, EmilAbderhalden-Str. 26-27, Martin-LutherUniversity Halle-Wittenberg, 06099 Halle (Saale), Germany

Tel +49345 5524358

Fax +49 3455527218

Email bernd.leplow@psych.uni-halle.de
This article was published in the following Dove Press journal:

Patient Preference and Adherence

14 September 2017

Number of times this article has been viewed

Background: Differential effects of botulinum toxin (BoNT) treatment in cervical dystonia (CD) and blepharospasm (BSP) treatment satisfaction and emotional responses to a life with a disabling condition were investigated. Special interest was drawn to the course within a BoNT treatment cycle and the effects of subjective well-being vs perceived intensity of motor symptoms and quality of life.

Methods: A questionnaire was distributed among $372 \mathrm{CD}$ patients and $125 \mathrm{BSP}$ patients, recruited from 13 BoNT centers throughout Germany. Items were related to dystonic symptoms, BoNT treatment responses and treatment satisfaction, quality of life, working situation, and emotional reactions to a life with dystonia.

Results: CD patients and BSP patients were widely satisfied with BoNT treatment, but treatment satisfaction worsened significantly within the treatment cycle. Especially CD patients reported that both the dystonic symptoms and the effects of BoNT treatment were influenced by emotional factors. Despite good overall treatment effects, patients from both groups perceived marked persistence of motor symptoms, restrictions of everyday life functions, and reduced quality of life. Functional amelioration of motor symptoms and emotional well-being were only moderately correlated. About $22 \%$ of patients from both groups reported mental disorders or emotional disturbances prior to the onset of dystonia.

Conclusion: As numerous psychological factors determine perceived outcome, BoNT treatment should be further improved by patient's education strategies enhancing behavioral self-control. From the patient's perspective, individual intervals, which may avoid exacerbation between injection points, should be considered. Moreover, patients at risk, with reduced adherence and poor BoNT outcome, should be identified and addressed within psychoeducation.

Keywords: cervical dystonia, blepharospasm, botulinum toxin, adherence, treatment satisfaction

\section{Introduction}

The beneficial effects of botulinum toxin (BoNT) treatment are unquestionable. ${ }^{1-5}$ Nonetheless, despite its positive outcome regarding motor symptoms, the effects on quality of life are less clear. Numerous reports have shown that emotional well-being improved during BoNT treatment. ${ }^{6-11}$ However, a considerable number of studies have shown elevated prevalence rates for emotional disturbances and mental disorders in cervical dystonia (CD) patients and blepharospasm (BSP) patients, respectively. Most frequent are anxiety, depression, social phobia, and avoidance behavior. Prevalence rates for anxiety and depression are usually reported to be between $40 \%$ and $60 \%$ for CD patients and BSP patients, respectively. ${ }^{12-20}$ In CD patients, social phobia is increased by as much as ten times. ${ }^{21,22}$ 
Whether or not these emotional disorders are reactions to dystonic syndromes (ie, adaptation disorders), perceived insufficiency of BoNT treatment or premorbid load is still unclear. Lencer et $\mathrm{a}^{15}$ reported that only social phobias are reactive to dystonia. Moraru et $\mathrm{al}^{16}$ outlined that $42.5 \%$ of patients investigated by standardized clinical interview reported at least one mental disorder prior to dystonia onset. In the Fabbrini et al study, ${ }^{13}$ this rate was $39.3 \%$ out of 89 patients with focal dystonias. Lifetime prevalence for any neuropsychiatric or personality disorder was estimated to be $71 \% .^{15}$

Despite the positive overall BoNT treatment outcome, the course of this effect varies widely between injection points. ${ }^{23}$ Thus, toward the end of a treatment cycle, therapeutic effect wanes. As a consequence, pain, motor disability, stigma experiences, and negative mood return. Werle et $\mathrm{al}^{24}$ have shown that negative side effects of waning severely affect leisure activities, family and social life, and emotional well-being. Thus, emotional burden remains despite overall effective symptomatic treatment. ${ }^{25}$

Assessments of emotional well-being strongly depend on the time of investigation within a treatment cycle. Especially in programs with fixed injection intervals, pain and motor disability return during waning of BoNT effects. During this time, many patients seek adjuvant treatments, which are deemed to ameliorate their symptoms..$^{26-29}$

Moreover, dystonic patients often experience significant impact of situational, emotional, and behavioral factors on their motor symptoms. The emotional impact on dystonia has been well known since the beginning of the last century..$^{30-34}$ In selected patients, these factors may, in part, overshadow the effects of BoNT treatment and, in turn, may enhance dysfunctional coping and decrease adherence, respectively.

It is well known in clinical neuropsychology that lessening of symptom severity and emotional well-being are only loosely correlated. Müller et a ${ }^{17}$ have shown that reduced quality of life persists despite good improvements in BoNT treatment. ${ }^{8,29}$ Moreover, mental disorders have the largest contribution for disability. ${ }^{35}$ Decreased quality of life mostly depends on depression ${ }^{11}$ or both on depression and anxiety. ${ }^{20}$ Overall, it has been shown that quality of life depends more on depression than on motor disability, or on the effects of BoNT. ${ }^{711,18,22,34,36,37}$ Depression itself seems to be due to stigma, poor body image, and reduced self-esteem. ${ }^{37-39}$

Thus, due to the variety of factors influencing treatment satisfaction, we addressed three questions: First, we wanted to know whether or not $\mathrm{CD}$ and BSP patients respond differentially to BoNT treatment and its implications on everyday activities. Second, we investigated the course of BoNT effects between injections and the perceived influence of emotional and behavioral factors on BoNT-associated amelioration and exacerbation of motor symptoms. Finally, we wanted to describe the relationship between perceived symptom amelioration and emotional well-being in these two patient groups.

\section{Methods \\ Study design}

Treatment satisfaction and emotional responses were investigated in patients with dystonia undergoing BoNT treatment. Thirteen BoNT centers, both in-patient units and out-patient centers, were approached in order to gain better insight into patient satisfaction through a survey for patients and their treating neurologists. Centers were distributed throughout Germany. After informed consent was obtained, patients received a questionnaire, which was sampled by their respective BoNT centers and sent to the department of psychology at Martin-Luther-University, where data analysis was performed.

This market research study was conducted under consideration of the "Code of Conduct" published by the European Pharmaceutical Market Research Association. All patients provided voluntary, informed consent to data collection and use, based upon a clear understanding of the purpose of the data collection and the use to which the data will be put. Thus, patients were completely briefed about the purpose of the study and could reject their participation without any consequences for their BoNT treatment or any other medical or psychological intervention. No invasive research, human testing, or access to patients' records were required in the recruitment or data collection. No personal data that allowed patient identification were obtained, nor were pseudonyms or codes noted in the protocols. Thus, both the medical staff and the investigators were completely blind with respect to patient identity.

\section{Participant recruitment}

Only patients with verified dystonia were recruited. No preselection with respect to sociodemographic variables, physical, or mental comorbidity or type of BoNT was done. Patients were excluded if they were not able to understand the instructions and if they were unable to read or to fluently communicate in the German language.

\section{Data collection}

The questionnaire contained items related to dystonic symptoms, BoNT treatment characteristics, the patients' 
subjective report to BoNT treatment, their quality of life, working situation, and emotional reactions to a life with dystonia, and BoNT treatment response, respectively.

Subjective assessments were obtained using six-point rating scales that reflected the grading system used in German schools. In this system, a score of " 1 " reflects an optimum performance, and a " 6 " is given in cases of complete failure. This system was used to help patients to anchor their respective ratings, especially if they were not used to grading inner experiences.

\section{Data analysis}

In this report, only $\mathrm{CD}$ and BSP patients were compared with respect to medical and subjective variables, reflecting treatment efficacy and the patient's satisfaction with treatment outcome. Group differences for metric variables were analyzed by means of two-tailed $t$-test statistics (alpha $<0.05$ ). Within-group comparisons were performed using paired $t$-test statistics. Dichotomous variables were analyzed using chi-square tests. Pearson's correlations were performed for metric and ordinal variables, respectively.

\section{Compliance with ethical standards}

All procedures performed in studies involving human participants were in accordance with the ethical standards of the institutional and/or national research committee and with the 1964 Helsinki Declaration and its later amendments or comparable ethical standards.

\section{Results \\ Participants}

Overall, 547 patients were recruited, in which $68.0 \%$ (372) of them were diagnosed with $\mathrm{CD}$ and $22.9 \%$ (125) were diagnosed with BSP. A minority, made up of 25 patients (4.6\%), had various focal, segmental, and generalized dystonias, respectively. Another group of 25 patients displayed dystonic signs, but did not meet diagnostic criteria of dystonia. In this report, only $\mathrm{CD}$ and $\mathrm{BP}$ patients were analyzed with respect to their respective experiences of dystonic symptoms and treatment characteristics.

\section{Medical and sociodemographic data}

The sex rates are widely equivalent between groups. Table 1 shows that CD patients are about 9 years younger than BSP patients, and have a higher unemployment rate due to dystonia. Though a higher rate of $C D$ patients reported restored capacity to work because of BoNT treatment, more CD patients than BSP patients (55.7 vs 37.3\%) still claimed decreased efficacy at work because of dystonia, and the respective necessity to shift work (Table 2). CD patients and BSP patients had equivalent years of education. Only a minority of patients were members of a patient's self-help group (CD: 10.6\%, BSP: 6.0\%).

In both groups, duration of dystonia was about 10 years (Table 3). First signs of dystonia preceded diagnosis by 3.2 years, both in CD patients and BSP patients, respectively. Figure 1 shows that, independent of BoNT treatment, CD patients perceived their courses of symptoms as becoming gradually better, whereas considerably more BSP patients than $\mathrm{CD}$ patients perceived no change of dystonia severity $(P=0.021)$. Forty-five percent of $\mathrm{CD}$ patients, compared to $24 \%$ of BSP patients, reported symptom aggravation in conditions of negative stress, emotional disturbances, and lack of sleep $(P<0.0001)$. More BSP patients $(14.4 \%)$ vs $\mathrm{CD}(3.8 \%)$ claimed that cold weather, bright light, and wind worsened their symptoms $(P<0.0001)$. Physical exhaustion aggravated dystonic symptoms in $11.3 \%$ of $C D$ patients and in $4.8 \%$ BSP patients $(P=0.034)$. Only a minority of the patients reported that positive feelings, relaxation, and good sleep ameliorated their medical situation (CD: 21.5\%, BSP: $13.5 \%, P=0.054$ ).

About 20\% of CD and BSP patients, respectively, reported mental disorders prior to onset of dystonia, which

Table I Patient's demographics and characteristics

\begin{tabular}{|c|c|c|c|}
\hline & Cervical dystonia & Blepharospasm & $P$-value \\
\hline Female, n (\%) & $243(66.8)$ & $79(56.3)$ & ns \\
\hline Mean age (n, SD, range) & $56.5(359,12.5 ; 20-91)$ & $65.2(121,12.7 ; 24-87)$ & $<0.0001$ \\
\hline \multicolumn{4}{|l|}{ Age group (years), n (\%) } \\
\hline $25-34$ & $21(5.9)$ & $\mathrm{I}(0.8)$ & \\
\hline $35-44$ & $27(7.5)$ & $9(7.5)$ & \\
\hline $45-54$ & $112(31.3)$ & $16(13.3)$ & \\
\hline $55-64$ & $106(29.6)$ & $20(16.7)$ & \\
\hline$\geq 65$ & $92(25.7)$ & $74(61.7)$ & \\
\hline $\begin{array}{l}\text { Mean years of education } \\
\text { (n, SD, range) }\end{array}$ & II.I (327, 3.9; 8-19) & $10.8(105,3.6 ; 8-19)$ & ns \\
\hline
\end{tabular}

Abbreviation: ns, not significant. 
Table 2 Patient's work situation

\begin{tabular}{llll}
\hline & Cervical dystonia & Blepharospasm & P-value \\
\hline Retirement not associated with dystonia, $\mathrm{n}(\%)$ & $191(52.0)$ & $89(74.2)$ & $<0.000 \mathrm{I}$ \\
Reduction of weekly work hours, $\mathrm{n}(\%)$ & $85(25.6)$ & $20(18.7)$ & $\mathrm{ns}$ \\
Shifting type of work because of dystonia, $\mathrm{n}(\%)$ & $48(14.5)$ & $8(7.1)$ & 0.042 \\
Decreased efficacy at work because of dystonia, $\mathrm{n}(\%)$ & $180(55.7)$ & $41(37.3)$ & $<0.00 \mathrm{I}$ \\
Unemployment due to dystonia, $\mathrm{n}(\%)$ & $56(16.0)$ & $8(7.3)$ & 0.021 \\
Restored capacity to work because of BoNT, $\mathrm{n}(\%)$ & $141(47.2)$ & $33(36.7)$ & 0.079 \\
\hline
\end{tabular}

Abbreviations: BoNT, botulinum toxin; ns, not significant.

were "severe enough to seek for medical or psychological help" (CD 19.8\%, BSP 22.0\%, not significant [ns]). Emotional hassles were also present in $23.9 \%$ of the $\mathrm{CD}$ patients and $24.4 \%$ of the BSP patients (ns), respectively. For those patients who could report onset of either emotional hassles or mental disorders (Table 3, emotional hassles and mental disorders), psychological factors preceded diagnosis of dystonia by about 7 years. On an average, these psychological factors preceded the first signs of dystonia by 5 years.

\section{Treatment variables}

In all patients, BoNT was well tolerated. Both groups received about 8 years of BoNT treatment (Table 3). Thus, treatment started slightly $>1$ year following diagnosis of dystonia (CD: 1.8 years; BSP: 1.1 years). Patients needed 3.9 (CD) vs 3.2 (BSP) injections until optimal response was reached. Both groups equivalently needed about 12 weeks for the injection-cycle length. Regular BoNT administration was possible in $80.1 \%$ of $\mathrm{CD}$ and $78.4 \%$ of BSP patients. Overall, CD patients experienced significantly more conditions that improved BoNT treatment: Relaxation: $25.3 \% \mathrm{CD}$ vs $12.0 \% \mathrm{BSP}(P=0.002)$; warm weather: $11.3 \% \mathrm{CD}$ vs $4.8 \% \mathrm{BSP}(P=0.05)$. CD patients also experienced more conditions that negatively influenced BoNT outcome: Stress, emotional hassles, lack of sleep $33.6 \%$ vs BSP $21.6 \%(P=0.012)$. Figure 2 shows that $35.0 \%$ of $\mathrm{CD}$ patients vs $22.8 \%$ of BSP patients rated their expectations regarding BoNT efficacy as not being fully fulfilled, whereas $53.7 \%$ of CD patients compared to $64.9 \%$ of BSP patients reported that their expectations were widely fulfilled $(P=0.049)$.

The BoNT pharmaceutical administered was not known by $46.8 \%$ (CD) and $44.2 \%$ (BSP) of the patients. In the remaining patient groups, the order of patients receiving OnabotulinumtoxinA, IncobotulinumtoxinA, AbobotulinumtoxinA was $50.6 \%, 33.3 \%$, and $16.1 \%$ in $\mathrm{CD}$ patients, and $67.2 \%, 21.3 \%$, and $11.5 \%$ in BSP patients. Type of BoNT did not affect any variable regarding treatment satisfaction, coping, or emotional dysfunction. Overall, $84.0 \%$ of the patients did not have any difficulty coming to a BoNT center. Those who had problems gaining BoNT access had to drive up to $400 \mathrm{~km}$.

\section{Treatment satisfaction}

Treatment satisfaction was good in both patient groups. The six-point scale yielded mean scores of 2.3 for $\mathrm{CD}$ patients and BSP patients, respectively (Figure 3). Outcome satisfaction varied considerably across treatment cycle (Figure 4). Though treatment maximum was rated about 2.1 in both patient groups, this score dropped to moderate satisfaction in the midst of the cycle and reached unsatisfactory ratings of 4.3 in CD patients and 4.2 in BSP patients immediately

Table 3 Medical variables and BoNT treatment characteristics

\begin{tabular}{|c|c|c|c|}
\hline & Cervical dystonia & Blepharospasm & $P$-value \\
\hline Mean years since diagnosis of dystonia (n, SD, range) & $10.6(336,8.4 ; 0.26-4.4 \mathrm{I})$ & $9.3(117,6.4 ; 0.19-27.4)$ & ns \\
\hline Mean years since first signs of dystonia ( $n, S D$, range) & I3.8 $(354,9.9 ; 0.26-53.3)$ & $12.5(117,9.8 ; 0.63-73.2)$ & ns \\
\hline Mean years of BoNT (n, SD, range) & $8.8(342,6.7 ; 0.18-34.3)$ & $8.2(120,6.3 ; 0.10-27.4)$ & ns \\
\hline Mean weeks between injections ( $n, S D$, range) & $12.1(358,2.1 ; 4.00-28.0)$ & $11.8(121,3.4 ; 2.0-24.0)$ & ns \\
\hline $\begin{array}{l}\text { Mean no of injections until optimal response } \\
\text { (n, SD, range) }\end{array}$ & $3.9(198,3.1 ; 1.00-25.0)$ & $3.2(52,2.3 ; 1.0-11.0)$ & ns \\
\hline Emotional hassles prior to dystonia $(\mathrm{n}, \%)$ & $84(23.9)$ & $29(24.4)$ & ns \\
\hline Mental disorders prior to dystonia (n, \%) & $69(19.8)$ & $26(22.0)$ & ns \\
\hline $\begin{array}{l}\text { Mean years of emotional hassles/mental disorders } \\
\text { prior to diagnosis ( } n, S D \text {, range) }\end{array}$ & $7.36(58,10.80 ; 0.00-66)$ & $7.74(19,10.5 ; 0.00-31)$ & ns \\
\hline
\end{tabular}

Abbreviations: BoNT, botulinum toxin; ns, not significant. 


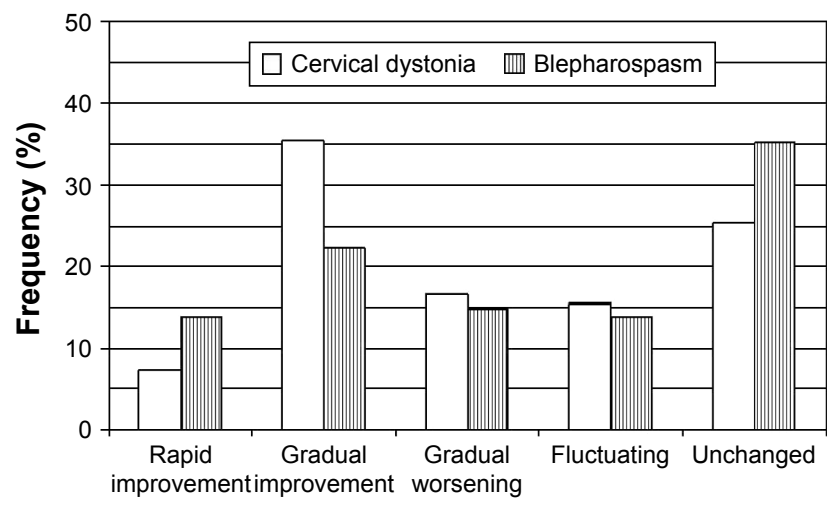

Figure I Course of dystonia over years: subjective perception (\%).

before BoNT administration. The two patient groups did not differ significantly in these ratings.

Satisfaction with BoNT treatment correlated significantly, but only moderately, with perceived symptom severity (Pearson's r; $\mathrm{CD}=0.34, P<0.0001$; $\mathrm{BSP}=0.27, P=0.006$ ). Despite this, treatment satisfaction was rated good in both patient groups, and perceived symptom intensity was rated within the medium range of the scale, with scores of about 3.4 in both groups (ns). Quality of life was also rated only moderate in both patient groups (CD: 3.1 ; BSP: 2.8 ; ns). Significant but moderate correlations were also found between satisfaction with BoNT treatment and quality of life (CD: $\mathrm{r}=0.39, P<0.0001$; BSP: $0.42, P<0.0001$ ).

On average, both CD patients and BSP patients (ns) perceived moderate restrictions in various domains of their lives (Figure 5). Again, significant but only moderate correlations were found between satisfaction with BoNT treatment and restrictions (CD: $\mathrm{r}=-0.36, P<0.0001$; BSP: $\mathrm{r}=-0.30$, $P=0.002)$. The order of domains where patients experienced their handicap due to dystonia was the working place, followed by leisure activities, social interactions, and home activities, respectively. The only significant difference between dystonia groups was found with respect to workplace

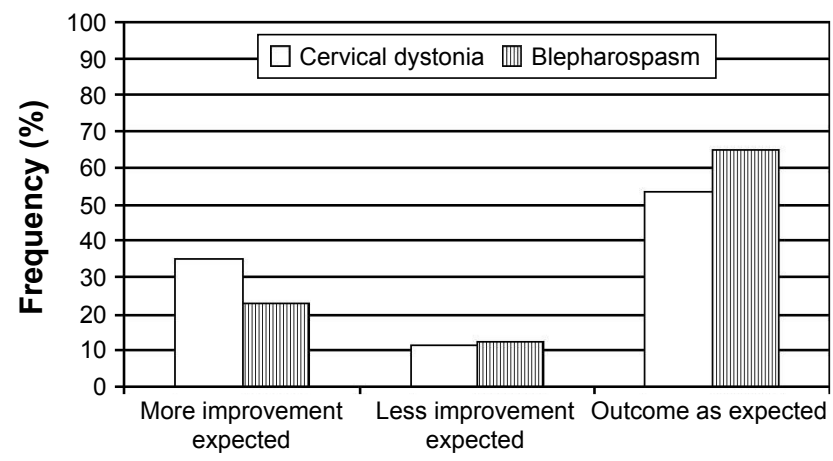

Figure 2 Expectations about botulinum toxin therapy (\%).

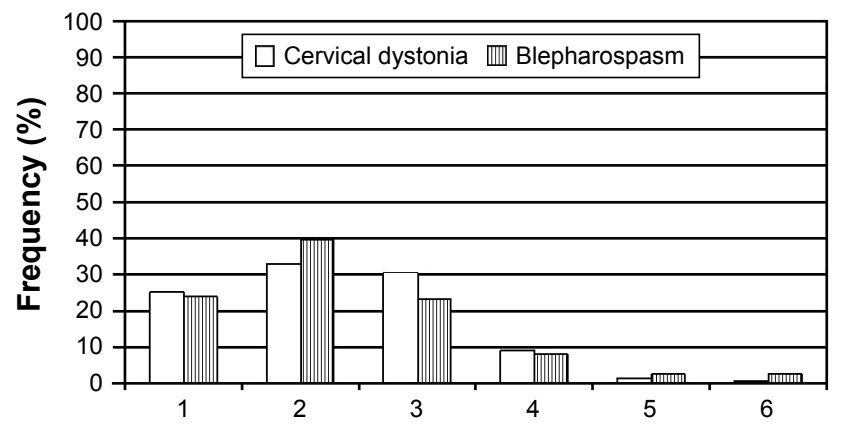

Figure 3 Perceived efficacy of botulinum toxin therapy (\%). Note: I= best outcome, $6=$ worst outcome.

activities, where a higher proportion of $C D$ patients compared to BSP patients felt markedly restricted $(P=0.01)$. For CD patients, a score above 3.49 indicated the upper quartile of those 80 patients who felt severely restricted in everyday activities. In BSP patients, the upper quartile indicated 31 patients above a score of 3.24.

\section{Suggestions for optimization}

Despite satisfaction with BoNT, treatment was generally perceived as good, and patients strongly recommended optimization of treatment procedures. Both groups claimed better organization of appointments $(4.6 ; 1=$ not at all important; $6=$ strong recommendation), shorter waiting times (4.3), individual scheduling of injection times (4.3), longer consultation times with their doctors (4.1), less changes within the medical staff (4.4), and more written information about dystonia, its treatment, and adjuvant therapies, and how to live with dystonia (3.5-4.2).

\section{Discussion}

Our results show that both CD patients and BSP patients were widely satisfied with the outcome of BoNT treatment. However, satisfaction varied widely within the treatment cycle. Like in the Mueller et $a{ }^{17}$ study, overall

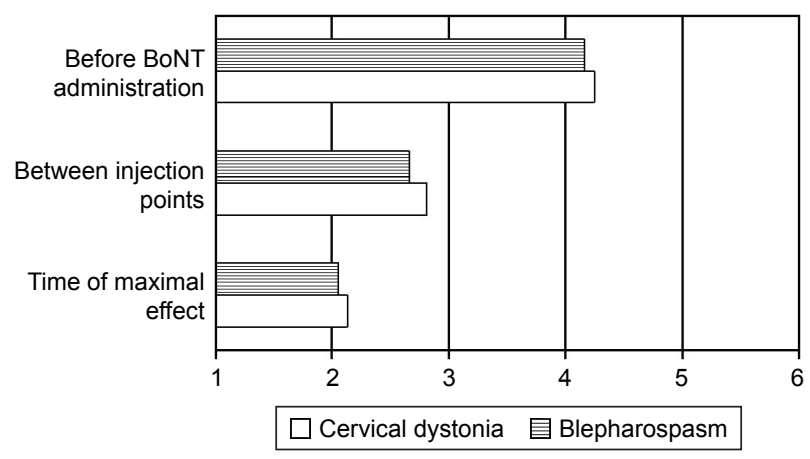

Figure 4 Perceived BoNT effect within treatment cycles (mean).

Note: I= best outcome, 6= worst outcome.

Abbreviation: BoNT, botulinum toxin. 


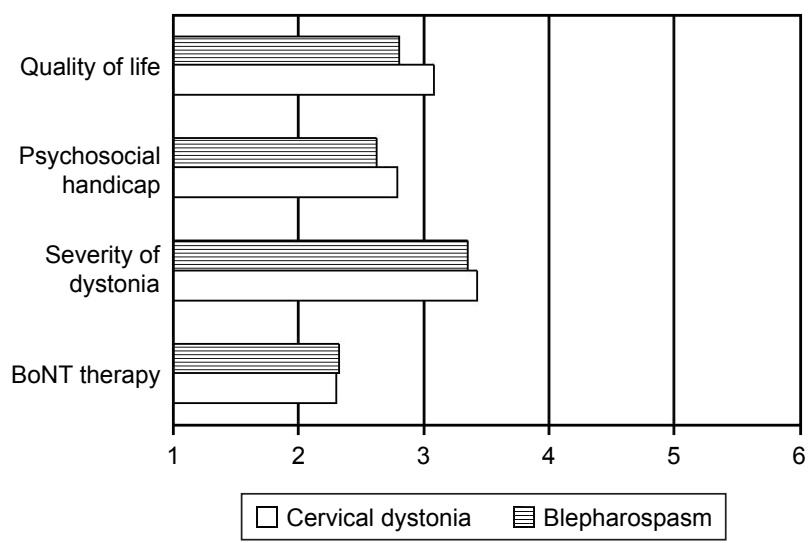

Figure 5 Satisfaction with BoNT treatment, symptom severity, psychosocial situation, and quality of life (mean).

Note: I= extremely satisfied, $6=$ not at all satisfied

Abbreviation: BoNT, botulinum toxin.

treatment satisfaction in both patient groups was associated with perceived moderate persistence of motor symptoms, restrictions of everyday life functions, and reduced quality of life, respectively. Especially CD patients reported that both the dystonic symptoms and the effects of BoNT treatment were positively and negatively influenced by emotional and situational factors.

CD patients were significantly younger than BSP patients, but CD patients were comparable to BSP patients with respect to education, duration of disease, duration since first signs of dystonia, and BoNT treatment duration. Due to their younger ages, $\mathrm{CD}$ patients reported more problems within their working affiliations despite the fact that a considerable number of patients returned to work because of effective BoNT treatment. Our data about the impact of CD symptoms on employment status, and the beneficial effects of BoNT on employment parameters confirm earlier research. ${ }^{40}$ In our study, BoNT treatment variables were comparable between groups. Both CD patients and BSP patients needed about 3.5 injections for optimal response, and cycle lengths were 12 weeks, which is in accordance with the literature..$^{41,42}$ In both groups, a rate of $22 \%$ of the patients with emotional problems prior to dystonia was found. No preselection with respect to sociodemographic and medical treatment variables was done, and BoNT centers were scattered across Germany. Thus, both patient groups are widely representative to their respective diagnostic groups.

CD patients seemed to be more prone to emotional and behavioral factors influencing their dystonic symptoms. Despite the fact that nearly $50 \%$ of these patients could return to work because of the beneficial effects of BoNT treatment and because the general course of the disease ameliorated over time (Figure 1), a high proportion of these patients expected an even better outcome. CD patients were also more affected by situational, emotional, and behavioral factors, which both ameliorated and aggravated their symptoms over the course of BoNT treatment. This is important because CD patients claimed that efficacy of BoNT treatment, in part, depends on these factors.

This investigation has shown that both patient groups are widely satisfied by BoNT treatment. Despite this positive effect, efficacy of BoNT dropped significantly within the 12-week treatment cycle (Figure 4). Moreover, a majority of CD patients reported exacerbation of symptoms associated with situational and emotional factors. Thus, despite good treatment satisfaction, both groups reported a moderate degree of persistent symptom intensity. Patients also reported ongoing disabling restrictions within everyday activities (Figure 5).

This outcome is in contrast to the majority of papers reporting increasing quality-of-life scores alongside reduced motor disability. ${ }^{7,12,26}$ Nevertheless, these results have to be interpreted cautiously because the assessments are often done shortly before and after BoNT injections. In this case, the beneficial BoNT effect may not reflect the time span between injection points. BoNT treatment effect sharply drops within the midst of the treatment interval (Figure 4). Obviously, patients do not only wait until their next injections, but try a vast number of adjuvant, nonmedical, and paramedical therapies to ameliorate their symptoms. ${ }^{17,28,29}$ They are usually rewarded by beneficial short-term effects of these interventions.

As a consequence, about $20 \%$ of the patients do not adhere to regular visits in a BoNT center, are disappointed because of the lack of an optimal outcome, and try to further enhance their situation with even more doctor visits, excessive use of adjuvant therapies, and paramedical services. In these patients, the courses of their dystonias over time seemed to be widely unrelated to BoNT administration. ${ }^{6}$ Moreover, about $22 \%$ of the patients of both groups reported emotional distress 7 years before dystonia onset. Emotional symptoms preceded first signs of dystonia by an average of about 5 years. Thus, emotional burden in dystonia is not exclusively reactive to a disabling disorder. It may be assumed that these disorders (ie, sleeplessness, anxiety, dysphoria, depression, and so on) were behavioral precursors, which accompany the gradual emergence of a neurological disorder. Predystonic mental disorders or emotional disturbances were also found in the Moraru et $\mathrm{al}^{16}$ and Fabbrini et al ${ }^{13}$ studies. Whether these patients represent a subgroup at risk for unstable adherence will be a matter of further research. 
Moreover, it is still unclear whether or not the effects of emotional burden can be ameliorated by flexible injection intervals, and thus dampen BoNT waning. From a pharmacological point of view, flexible injection intervals may be possible without the emergence of tolerance or an enhanced rate of adverse events. ${ }^{9,43-45,47}$ Truong ${ }^{46}$ for example, recommends injection intervals ranging from 6 weeks up to 20 weeks for selected patients. Up to now, it is unclear which type of patients may profit from shortened or prolonged injection intervals.

From a psychological point of view, it is important that time points are not scheduled along perceived burden. Like in pain medication, patients then may learn to obtain relief by means of a pharmacological tool, with the fatal consequence that pain thresholds, tolerance of symptom intensities, and usability of self-control strategies decrease. With respect to dystonia, many of these patients deem BoNT as not sufficiently effective at least toward the end of a treatment cycle and seek additional treatments. These treatments are often not proved, and they are expensive, potentially harmful, and contain unknown side effects. ${ }^{17}$ Thus, further research has to identify those patient groups who may especially benefit from individualized injection intervals. In any case, individual injection intervals should be fixed for each respective patient.

Finally, basic research in clinical neuropsychology has unequivocally shown that objective assessments of disease severity are only moderately correlated with subjective perceptions of symptom intensity, restrictions of activities in everyday activities, and quality of life, respectively. Thus, physicians' assessments of disease severity do not always match the patients' perceptions of BoNT-related improvements. ${ }^{9}$ Such a dissociation between decreased motor disability and persisting psychological malfunctioning has also been shown by Müller et al. ${ }^{17}$ Research has also demonstrated a dissociation between perceived improvements of motor functioning and persisting handicaps in leisure activities, social functioning, and employment activities. ${ }^{6}$

A major reason for this dissociation seems to be depression and related mental disorders. ${ }^{9,27,34}$ As mentioned already in the introduction, prevalence rates of both mental disorders and emotional burden is much higher in dystonia patients than in the general population. Moreover, associations between motor improvements and quality of life reported in the literature are mostly moderate. This has been clearly shown in our results, where correlation coefficients between 0.27 and 0.42 mean that the respective variables have only $7 \%-18 \%$ of their variances in common. This is in accordance with the literature. For example, in the Hefter et al study, ${ }^{25}$ the correlation coefficient between motor function and quality of life was 0.26 . Despite the fact that this coefficient was also significantly different from zero, it means that motor function and quality of life only have $7 \%$ of their variances in common. In other words, $93 \%$ of the variation of quality of life is not explained by motor function. Therefore, psychological variables have a major impact on the perceived outcome of BoNT treatment. These factors should be addressed to adjuvant psychological treatments, such as focus group discussions. ${ }^{45}$

\section{Conclusion}

As dystonic symptoms worsen significantly toward the end of the BoNT injection intervals, and because improvement of motor symptoms alone does not account for optimal treatment satisfaction, four conclusions can be drawn from this investigation: First, organizational aspects of BoNT administration should be improved. Time for conversation with their doctors, where patients' needs are addressed, and where the the same experienced doctors who were acquainted with their patients and with their personal characteristics are present, were mostly wished for by the patients. Second, an important means of increasing BoNT treatment efficacy is enhancement of behavioral self-control of motor exacerbation, emotional dampening of disease-related stress, and the modification of emotional high-risk situations. The third means should be the identification of patients with pre-dystonic emotional disturbances and other risks for suboptimal BoNT outcome. Finally, some patients require shorter or longer BoNT treatment intervals, but should be treated in fixed schedules to avoid inadequate coping mechanism. ${ }^{47}$

\section{Acknowledgments}

The authors thank Mareike Thomas, student research assistant, for proof reading and compilation of the literature. Editing was supported by Anastasia Byler, PsychEdit Services, USA. This investigation was supported by Merz Pharmaceuticals.

\section{Disclosure}

The corresponding author (BL) was a consultant of Merz Pharmaceuticals for this investigation. In 2009, he was a consultant of Medtronic. He is an unsalaried member of the boards of the German Patient's Organisation for Parkinson's Disease (dPV), the German Society of Dystonia (DDG), and the German Society of Torticollis. For data collection and data analysis, JP was a salaried research assistant at 
Martin-Luther-University Halle-Wittenberg, Germany, sponsored by Merz Pharmaceuticals; AE was a student research assistant responsible for data preparation and salaried by Merz pharmaceuticals. The authors report no other conflicts of interest in this work.

\section{References}

1. Comella CL, Jankovic J, Truong DD, Hanschmann A, Grafe S; U.S. Xeomin Cervical Dystonia Study Group. Efficacy and safety of incobotulinumtoxinA (NT, 201, XEOMIN ${ }^{\circledR}$, botulinum neurotoxin type A, without accessory proteins) in patients with cervical dystonia. J Neurol Sci. 2011;308(1-2):103-109.

2. Truong D, Duane DD, Jankovic J, et al. Efficacy and safety of botulinum type A toxin (Dysport) in cervical dystonia: results of the first US randomized, double-blind, placebo-controlled study. Mov Disord. 2005;20(7):783-791.

3. Costa J, Espirito-Santo C, Borges A, et al. Botulinum type B for cervical dystonia. Cochrane Database Syst Rev. 2005;25(1):CD004315.

4. Mills RR, Pagan FL. Patient considerations in the treatment of cervical dystonia: focus on botulinum type A. Patient Pref Adherence. 2015;9: $725-731$.

5. Simpson DM, Blitzer A, Brashear A, et al. Assessment: Botulinum neurotoxin for the treatment of movement disorders (an evidence-based review). Neurology. 2008;70(19):1690-1706.

6. Mordin M, Masaquel C, Abbott C, Merriman CC. Factors affecting the health-related quality of life of patients with cervical dystonia and impact of treatment with botulinumtoxin A (Dysport): results from a randomised, double-blind, placebo-controlled study. BMJ. 2014;4:e005150.

7. Slawek J, Friedman A, Potulska A, et al. Factors affecting the healthrelated quality of life of patients with cervical dystonia and the impact of botulinum toxin type A injections. Funct Neurol. 2007;22(2):95-100.

8. Albanese A, Abbruzzese G, Dressler D, et al. Practical guidance for CD management involving treatment of botulinum toxin: a consensus statement. J Neurol. 2015;262(10):2201-2213.

9. Fernandez H, Pagan F, Danisi F, et al. Prospective study evaluating incobotulinumtoxinA for cervical dystonia or blepharospasm: interim results from the first 145 subjects with cervical dystonia. Tremor Other Hyperkinetic Mov (N Y). 2013;3.

10. Hilker R, Scgischniaschvili M, Ghaemi M, Jacobs A, Rudolf J. Health related quality of life is improved bybotulinum neurotoxin type $\mathrm{A}$ in long term treated patients with focal dystonia. J Neurol Neurosurg Psychiatry. 2001;71(2):193-199.

11. Skogseid IM, Malt UF, Røislien J, Kerty E. Determinants and status of quality of life after long-term botulinum therapy for cervical dystonia. Europ J Neurol. 2007;14(10):1129-1137.

12. Conte A, Berardelli I, Ferrazzano G, Pasquini M, Berardelli A, Fabbrini G. Non-motor symptoms in patients with adult-onset focal dystonia: sensory and psychiatric disturbances. Parkinsonism Relat Disord. 2016; 22(Suppl 1):S111-S114.

13. Fabbrini G, Berardelli I, Moretti G, et al. Psychiatric disorders in adult-onset focal dystonia: a case-controlled study. Mov Disord. 2010; 25(4):459-465.

14. Hall TA, McGwin G, Searcey K, et al. Health-related quality of life and psychosocial characteristics of patients with benign essential blepharospasm. Arch Ophthalmol. 2006;124(1):116-119.

15. Lencer R, Steinlechner S, Stahlberg J, et al. Primary focal dystonia: evidence for distinct neuropsychiatric and personality profiles. J Neurol Neurosurg Psychiatry. 2009;80(10):1176-1179.

16. Moraru E, Schnider P, Wimmer A, et al. Relation between depression and anxiety in dystonic patients: implications for clinical management. Depression Anxiety. 2002;16(3):100-113.

17. Müller J, Kemmler G, Wissel J, et al. The impact of blepharospasm and cervical dystonia on health related quality of life and depression. J Neurol. 2002;249(7):842-846.
18. Page D, Butler A, Jahanshahi M. Quality of life in focal, segmental, and generalized dystonia. Mov Disord. 2007;22(3):341-347.

19. Tomic S, Petkovic I, Pucic T, Resan B, Juric S, Rotim T. Cervical dystonia and quality of life. Acta Neurol Belg. 2016;116(4):589-592.

20. Pekmezovic T, Svetel M, Ivanovic N, et al. Quality of life in patients with focal dystonia. Clin Neurol Neurosurg. 2009;111(2):161-164.

21. Gündel H, Wolf A, Xidara V, Busch R, Ceballos-Baumann AO. Social phobia in spasmodic torticollis. J Neurol Neurosurg Psychiatry. 2001;71(4):499-504.

22. Ozel-Kizil ET, Akbostanci MC, Ozguven HD, Atbasoglu EC. Secondary social anxiety in hyperkinesia. Mov Disord. 2008;23(5):641-645.

23. Hallett M, Albanese A, Dressler D, et al. Evidence-based review and assessment of botulinum neurotoxin for the treatment of movement disorders. Toxicon. 2013;67:94-114.

24. Werle RW, Takeda SY, Zonta MB, Guimarães AT, Teive HA. The physical, social and emotional aspects are the most affected in the quality of life of the patients with cervical dystonia. Arq Neuropsiquiatr. 2014;72(6):405-410.

25. Hefter H, Benecke R, Erbguth F, Jost W, Reichel G, Wissel J. An openlabel cohort study of the improvement of quality of life and pain in de novo cervical dystonia patients after injections with $500 \mathrm{U}$ botulinum toxinA (Dysport). BMJ Open. 2013;3(4):e001853.

26. Birner P, Schnider P, Müller J, Wissel J, Fuchs I, Auff E. Torticollis spasmodicus, Blepharospasmus und hemifazialerSpasmus, Subjektive Bewertungen der Therapie durch Patienten. [Spasmodic torticollis, blepharospasm, and hemifacial spasm - subjective therapy evaluations by patients]. Nervenarzt. 1999;70(10):903-908. German.

27. Junker J, Oberwittler C, Jackson D, Berger K. Utilization and perceived effectiveness of complementary and alternative medicine in patients with dystonia. Mov Disord. 2004;19(2):158-161.

28. Leplow B, Jersch M, Schönfeld R. Medizinische und nicht-medizinische Begleitbehandlungenzur Botulinum-Toxin-Therapie bei Torticollisspasmodicus Patienten. [Botulinum toxin therapy for spasmodic torticollis - medical and non-medical adjunct treatments]. Nervenarzt. 2013;84:493-497. German.

29. Leplow B, Wiemann J. Zwischen disability und handicap - Zur Frage der Therapietreuevon Torticollispatienten bei der Therapie mit Botulinumtoxin. [Between disability and handicap - to the question about compliance of spasmodic torticollis patients during botulinum toxin therapy]. Nervenheilkunde. 2010;28:519-525. German.

30. Meige H, Feindel E. Der Tic - Sein Wesen und seine Behandlung. [The Tic - Its Nature and Treatment]. 1903; Leipzig und Wien: Franz Deuticke. German.

31. Wartenberg R. Zur Klinik und Pathophysiologie der extrapyramidalen Bewegungsstörungen. [To the clinic and pathophysiology of extrapyramidal movement disorders]. Z Neurol. 1923;84:303-354. German.

32. Quadfasel F, Krayenbühl H. Über Haltungsstörungen und ihre Beeinflußbarkeit. [About posture disorders and their ability to influence]. Monatsschr Psychiatr. 1934;88:39-86. German.

33. Jahanshahi M. Factors that ameliorate or aggravate spasmodic torticollis. J Neurol Neurosurg Psychiatry. 2000;68(2):227-229.

34. Ben-Schlomo Y, Camfield L, Warner T. ESDE collaborative group. What are the determinants of quality of life in people with cervical dystonia? J Neurol Neurosurg Psychiatry. 2002;72(5):608-614.

35. van den Dool J, Tijssen MA, Koelman JH, Engelbert RH, Visser B. Determinants of disability in cervical dystonia. Parkinsonism Relat Disord. 2016;32:48-53.

36. Camfield L, Ben-Slomo Y, Warner TT; Epidemiological Study of Dystonia in Europe Collaborative Group. Impact of cervical dystonia on quality of life. Mov Disord. 2002;17(4):838-841.

37. Papathanasiou I, MacDonald L, Whurr R, Jahanshahi M. Perceived stigma in spasmodic torticollis. Mov Disord. 2001;16:280-285.

38. Lewis L, Butler A, Jahanshahi M. Depression in focal, segmental and generalized dystonia. J Neurol. 2008;255(11):1750-1755.

39. Jahanshahi M. Psychosocial factors and depression in torticollis. J Psychosom Res. 1991;35(4-5):493-507. 
40. Molho ES, Agarwal N, Regan K, Higgins DS, Factor SA. Effect of cervical dystonia on employment: a retrospective analysis of the ability of treatment to restore premorbid employment status. Mov Disord. 2009;24(9):1384-1387.

41. Dressler D, Tacik P, Adib Saberi F. Botulinum toxin therapy of cervical dystonia: comparing onabotulinumtoxin $\mathrm{A}\left(\right.$ Botox $\left.^{\circledR}\right)$ and incobotulinumtoxin A (Xeomin ${ }^{\circledR}$ ). J Neural Transm (Vienna). 2014;121(1):29-31.

42. Marsh WA, Monroe DM, Brin MF, Gallagher CJ. Systematic review and meta-analysis of the duration of clinical effect of onabotulinumtoxinA in cervical dystonia. BMC Neurol. 2014;14:91.

43. Evidente VG, Truong D, Jankovic J, Comella CL, Grafe S, Hanschmann A. IncobotulinumtoxinA $\left(\mathrm{Xeomin}^{\circledR}\right)$ injected for blepharospasm or cervical dystonia according to patient needs is well tolerated. J Neurol Sci. 2014;346(1-2):116-120.
44. Dressler D, Tacik P, Saberi FA. Botulinum toxin therapy of cervical dystonia: duration of therapeutic effects. J Neural Transm (Vienna). 2015;122(2):297-300.

45. Poliziani M, Koch M, Liu X. Striving for more good days: patient perspectives on botulinum toxin for the treatment of cervical dystonia. Patient Prefer Adherence. 2016;10:1601-1608.

46. Truong D. Botulinum neurotoxin and dystonia: a case for greater flexibility in treatment regimens? CNS. 2017;2(2):12-17.

47. Ojo OO, Fernandez HH. Is it time for flexibility in botulinum interinjection intervals?. Toxicon. 2015;107(Pt A):72-76.

Patient Preference and Adherence

\section{Publish your work in this journal}

Patient Preference and Adherence is an international, peer-reviewed, open access journal that focuses on the growing importance of patient preference and adherence throughout the therapeutic continuum. Patient satisfaction, acceptability, quality of life, compliance, persistence and their role in developing new therapeutic modalities and compounds to optimize clinical outcomes for existing disease states are major areas of interest for the journal. This journal has been accepted for indexing on PubMed Central. The manuscript management system is completely online and includes a very quick and fair peer-review system, which is all easy to use. Visit http://www. dovepress.com/testimonials.php to read real quotes from published authors.

\footnotetext{
Submit your manuscript here: http://www.dovepress.com/patient-preference-and-adherence-journal
} 